\title{
Association between echinococcosis-specific health literacy and behavioral intention to prevent echinococcosis among herdsmen on the Tibet Plateau in China
}

Jie Zhao

Fudan University School of Public Health https://orcid.org/0000-0001-6377-8803

\section{Yangzong Dawa}

Fudan University School of Philosophy

Cuo Deji

Center for Disease Control and Prevention of Gande Country

Bentai Deng

Center for Disease Control and Prevention of Gande Country

Bao Leng

Center for Disease Control and Prevention of Gande Country

\section{Zengyue Li}

Qinghai Provincial Institue for Endemic Disease Control and Prevention

\section{Wanli Chen}

Fudan University School of Public Health

Jiangya Wang

Fudan University School of Public Health

\section{Yuxin Zhang}

Fudan University School of Public Health

\section{Zhong Ake ( $\nabla$ akz1307@126.com )}

Qinghai Provincial Center for Disease Control and Prevention

Jiwei Wang ( $\boldsymbol{D}$ jiweiwang@fudan.edu.cn )

Fudan University School of Public Health

\section{Lizheng Shi}

Tulane University School of Public Health and Tropical Medicine

\section{Research Article}

Keywords: echinococcosis, health literacy, behavioral intention

Posted Date: May 27th, 2020 
DOI: https://doi.org/10.21203/rs.3.rs-30518/v1

License: (c) (i) This work is licensed under a Creative Commons Attribution 4.0 International License. Read Full License 


\section{Abstract \\ Background}

Echinococcosis is considered a neglected zoonotic disease. It has been an major worldwide health problem primarily affecting pastoral and poor rural communities with weak infrastructures, limited economic resources and poor sanitation. In general, the population in these poor areas has a low level of health literacy. This study aims to examine the association between echinococcosis-specific health literacy $(\mathrm{ES}-\mathrm{HL})$ and behavioral intention to prevent echinococcosis(BIPE) among herdsmen on the Tibet Plateauin in China.

\section{Methods}

A cross-sectional study of 401 Tibetan herdsmen was conducted in Gande country of Qinghai Province, China. Participants were recruited from August to September 2018 and from February to March 2019. A self-developed questionnaire was used to measure demographic information, ES-HL and BIPE. Hierarchical regression analysis was done to identify the factors associated with BIPE.

\section{Results}

In the hierarchical regression analysis, we entered age, sex, education level, marital state and family monthly income per capita into model 1 which explained a significant amount of variance in BIPE (Adjusted $R^{2}$ change $\left.=0.029, P=0.006\right)$, and $\operatorname{sex}(\beta=-0.125, P=0.013$ ) and family monthly income per $\operatorname{capita}(\beta=-0.133, P=0.009)$ were found to be associated with BIPE. Then three factors of ES-HL was added to Model 1 to create Model 2. In Model 2, the two factors of ES-HL, perceived echinococcosis information support $(\beta=0.229, P<0.001)$ and echinococcosis-specific self-management ability $(\beta=$ $0.252, P<0.001)$, were significantly associated with BIPE, while the information acquisition and evaluation ability factor $(\beta=0.093, P=0.089)$ was not found to be associated with BIPE. The model improved significantly when ES-HL was included (Model 2 ) explaining $25.8 \%$ of variance of BIPE(Adjust $\mathrm{R}^{2}$ change $\left.=0.229, \mathrm{P}<0.001\right)$

\section{Conclusions}

ES-HL is an important predictor of whether individuals take preventive actions against echinococcosis. ES-HL promotion action project should be developed aiming at different target population to enhance some of the specific abilities needed to prevent echinococcosis.

\section{Background}


Echinococcosis is a chronic cyst-forming and neglected zoonosis caused by infection with the larval stage of the genus Echinococcus (E.) [1]. Dogs and wild Canidae are the definitive hosts, while domestic Ungulates act as intermediate hosts[2]. The two most important forms, which are of medical and public health relevance in humans, are alveolar echinococcosis (AE) caused by E. multilocularis and cystic echinococcosis (CE) caused by E. granulosus [3]. In 2015, WHO estimated that echinococcosis is responsible for 19,300 deaths and an increase in disability-adjusted life years of approximately 871,000 people worldwide each year [4].

Since the mid-1990s detailed studies and field investigations on the Tibetan Plateau have revealed the epidemic of echinococcosis to be an under-reported major public health problem, particularly in the rural communities and some low socio-economic areas with poor sanitary facilities and limited resources in the eastern and central regions [5]. Human prevalence surveys showed that $\mathrm{CE}$ and $\mathrm{AE}$ are co-endemic with higher burdens of each disease on the Tibetan Plateau than other endemic world regions [6-7]. In some countries of the Tibetan Plateau, human incidence rates for echinococcosis can reach more than 50 per 100,000 person-years, and prevalence levels as high as $5 \%-12 \%$ may occur [8]. The prevalence levels of human AE in Ganze Tibetan Autonomous Prefecture which is one of the deep poverty areas in China are among the highest recorded anywhere in the world[9]. In livestock, the prevalence of echinococcosis found in slaughterhouses ranges from $20 \%-95 \%$ of slaughtered animals[10].

There are many social factors favouring the life cycle of E. multilocularis and E. granulosus. In China, Tibetan plateau is dominated by animal husbandry and stay at a lower socio-economic level. Most Tibetan herdsmen families keep at least $1 \mathrm{dog}$. They have a tradition of close contact with their pet dogs. Dog manure and cow dung are scattered around their tents. Women collect them by hand, dry them for fuel, make fire with dung cakes when cooking. These behaviors are important factors that favour the life cycle of E.. Moreover, water scarcity in the alpine pasture, insufficient hygienic awareness with poor hand washing habits, and hand-kneaded food increase the chances of eating insect eggs. Home slaughter and feeding of dogs with raw offals favour the parasite's life cycle. Furthermore, herdsmen are often reluctant for fear of hurting valuable animals, so they often refuse deworming dogs and vaccinating lambs. These lifestyle factors which are more likely to be determined by health literacy $(\mathrm{HL})$ increase the risk of echinococcus infection in humans, which in turn contributes to the prevalence of echinococcus in these pastoral and poor rural communities[11].

The World Health Organization defines $\mathrm{HL}$ as 'the cognitive and social skills which determine the motivation and ability of individuals to gain access to, understand, and use information in ways which promote and maintain good health [12]'. HL has been considered to be a primary goal of public health education and communication strategies[13]. Low levels of HL are associated with poor understanding of disease knowledge, resultant non-adherence to health behaviors, and infrequent use of preventative services, and ultimately, increased morbidity and mortality rates[14]. According to the US Department of Education, only twelve percent of US residents are with adequate HL[15]. This leads to fewer patient choices, safety risks, and an increased rate of hospitalizations[16]. Studies have shown that HL in patients with high-risk cardiovascular conditions such as hypertension and congestive heart failure is 
essential to self-care, especially in the most vulnerable populations[17]. Many studies showed that diabetes patients with poor $\mathrm{HL}$ had difficulties adhering to all aspects of treatment regimens because different knowledge and skills were required for unique aspects of the regimens[18-19]. Echinococcosisspecific health literacy (ES-HL) refers to the abilities that enable the acquisition and processing of information in association with echinococcosis and actively manage one's health for the prevention and control of echinococcosis. We hypothesized that ES-HL is an important determinant of echinococcosis related health behaviors. Now, few researches have considered the association between ES-HL and echinococcosis related health behaviors.

Behavioral intention is the key index of a person's mental readiness for action in several social psychological models of behavior. The intention construct has been employed extensively to understand social and applied issues[20]. According to the theory of reasoned action, intentions are the proximal predictors of behavior[21]. The theory of planned behavior also assumes that intentions are the most important predictor of behavior[22]. Moreover, a meta-analysis indicated that intentions explain $28 \%$ of the variance, on average, in future behavior[23]. It is sufficient to say that the prerequisite for a person to take preventive action against echinococcosis is his or her behavioral intention to prevent echinococcosis(BIPE).

This study aims to examine the association between ES-HL and BIPE among herdsmen on the Tibet Plateau in China, so as to help with designing and better focusing of future interventions aimed at improving people's echinococcosis related health behaviors and health outcomes.

\section{Methods}

\subsection{Recruitment}

The study was conducted in Gande county, Tibetan Autonomous Prefecture of Golog, Qinghai Province, China. Gande county is located in the Southeastern part of Qinghai Province and in the hinterland of the Tibet Plateau. The area of Gande country is about $7046.2 \mathrm{~km}^{2}$ with an average elevation higher than 4300 meters. Gander county is a national-level impoverished county with limited resources, poor sanitation and a large proportion of poor people. Its economy is dominated by animal husbandry. Gande county is composed of 36 townships. There are 8579 households (including 7671 shepherd households), with a total population of 38352 (including 32523 animal husbandry population people). The Tibetan population accounts for $98 \%$ of the total population. Their main religion is Tibetan Buddhism, and there is a total of 71 Tibetan Buddhist monasteries in Gande county.

In this study, a convenient sampling method was adopted to recruit the participants from August to September 2018 and from February to March 2019. Participants were recruited during religious activities in buddhist temples. The inclusion criteria included: 1) Tibetan herdsmen; 2) 18-70 years old; 3) no serious concurrent diseases; 4) no serious mental illness or cognitive impairment; 5) no communication disorder. Participants meeting the above inclusion criteria will be included in this study. Participants 
completed the questionnaire with the help of investigators who read the questions one by one and recorded the answers.A total of 640 people were surveyed, 550 questionnaires were collected, and 401 questionnaires were valid. The response rate were $85.9 \%$, and the valid rate was $72.9 \%$.

\subsection{Measurement \\ 2.2.1 Socio-demographic information}

Socio-demographic information including age, sex, education level, marital state, family monthly income per capita was collected with self-report questionnaires.

\subsubsection{Measurement of ES-HL}

ES-HL was measured by a self-developed scale which was based on "The Health Literacy Questionnaire (HLQ) [24]" and "The European health literacy survey (HLS-EU) [25]". The initial scale consists of 17 items designed to measure five ES-HL factors, namely "perceived echinococcosis information support(4items)", "information acquisition ability(3items) ", "information evaluation ability(3items)", "ability to actively communicate with health care providers(3items)", and "echinococcosis-specific self-management ability(4items)", and all items were rated on a 5-point Likert scale ranging from $1=$ disagree not at all to 5 = agree very strongly. The maximum and minimum score for each item are five point and one point, and the total score is the sum of all the item scores. In order to eliminate the impact of the number of items, scores for each dimension of health literacy were obtained by dividing the total score of each dimension by the number of items in each dimension. Therefore, the maximum score for each dimension is five point, the minimum score for each dimension is one point.

\subsubsection{Measurement of BIPE}

BIPE was also measured by a scale developed by our own. This scale contains a total of 11 items, and all items were rated on a 5 -point Likert scale ranging from $1=$ very reluctant to $5=$ very willing to.

Participants were asked how strongly they were willing to take preventive action against echinococcosis by the question, "Are you willing to participate in the government-sponsored screening for echinococcosis?", "Are you willing to deworm your dogs against echinococcosis?", "Are you willing to vaccinate your sheep against echinococcosis?", "Are you willing to participate in the health education program for the echinococcosis control organized by the government?", "Are you willing to participate in the health education program for echinococcosis control organized by the monasteries?", "Are you willing to keep the dog on a leash?", "Are you willing to bury your livestock?", "Are you willing to hand over your sick and dead livestock to the government?", "Are you willing to dispose of your dead livestock through celestial burial?","Are you willing to have your livestock slaughtered by the government rather than by yourself?", "Are you willing to bury the guts of a slaughtered animal rather than feed it to a dog?". The maximum score of each item is one point,and the total score is the sum of all the item scores. In this study, the Cronbach's a of the scale was 0.882 .

\subsection{Statistical analysis}


Descriptive statistics were used to summarize the demographic characteristics of participants. Explore factor analysis (EFA) of the principal components with varimax rotation was carried out on the ES-HL Scale. An eigenvalue $>1$ was used as a cut-off point to determine the applicability of the pre-designed factors of ES-HL. Items with factor loading $>0.5$ and conceptual relevance were used as criteria for retaining in a factor. Items with factor loadings $>0.4$ on two or more factors would be excluded. Pearson correlation analyses was used to preliminarily analyze the relationship between study variables. Hierarchical multiple regression was used to explore the association between ES-HL and BIPE with age, sex, degree of education, marital status and family monthly income per capita as control variables. Tolerance and variance inflation factors were used to diagnose multicollinearity among independent variables. When tolerance is less than 0.1 or variance inflation factor is greater than 10 , it would be considered that there is high multicollinearity among independent variables.

\section{Results}

\subsection{Demographic characteristics}

Table 1 summarizes the demographic characteristics of the respondents. In this study, 401 Tibetan pastoral residents were recruited. The mean age of the respondents is $38.61 \pm 13.31$ (mean \pm SD), and $49.1 \%$ were female. The majority $(74.6 \%)$ have just finished primary school or were illiterate, and $44.6 \%$ had a monthly income $<1000 \mathrm{CNY}(\approx 142 \mathrm{USD})$. More than $80 \%$ of respondents were married.

\subsection{Exploratory factor analysis}

Table 2 presents the factor loadings based on EFA, Cronbach's a, score mean and standard deviation for these factors. The results of KMO (kaiser-meyer-olkin) measurement (KMO value 0.935 ) and Bartlett's sphericity test $(P<0.001)$ confirmed the adequacy for the EFA. EFA of the initial scale yielded three factors that accounted for $70.38 \%$ of total variance. Two items of the initial scale with factor loadings $>$ 0.4 on two or more factors were deleted. After analyzing and categorizing the meanings of the factors and the items they contain, the three factors are named for perceived echinococcosis information support, information acquisition and evaluation ability and echinococcosis-specific self-management ability. Perceived echinococcosis information support(4 items) which contains the same items as the first dimension of the initial scale refers to the ability to obtain information support for echinococcosis control from health professionals, family members, friends, village cadres or other information channels. Information acquisition and evaluation ability ( 5 items) which mainly merges the second and the third factors of the initial scale refers to the ability to find information about echinococcosis independently and to make independent judgment and evaluation. Echinococcosis-specific self-management ability( 6 items) which mainly merges the forth and the fifth factors of the initial scale includes the abilities to communicate with medical personnel about echinococcosis, to participate in the screening of echinococcosis and to participate in some lectures and activities about echinococcosis control.

\subsection{Preliminary correlation analyses}


Table 3 summarizes the correlation among the demographic variables (sex, age, education level, marital status, family monthly income per capita) ,ES-HL and BIPE. It is indicated that sex, family monthly income per capita and ES-HL are correlated significantly with the BIPE.

\subsection{Hierarchical multiple regression analysis}

Table 4 reports the unstandardized $(B)$ and standardized $(\beta)$ regression coefficients for model 1 and model 2. For model 1, sex, age, education, marital status, income were entered into the model. Sex $(\beta=$ $-0.125, P=0.013)$ and family monthly income per capita $(\beta=-0.133, P=0.009)$ explained a significant amount of variance of $B I P E\left(\right.$ Adjust $\left.R^{2}=0.029, P=0.006\right)$. The model improved significantly when $E S-H L$ was included (Model 2) explaining 25.8\% of variance of $B I P E\left(A d j u s t R^{2}=0.229, P<0.001\right.$ ). In model 2, $\operatorname{sex}(\beta=-0.064, P=0.152)$ was no longer significantly related to $B I P E$, while family monthly income per capita $(\beta=-0.119, P=0.008)$ was still significantly related to BIPE. Perceived echinococcosis information support $(\beta=0.229, P<0.001)$ and echinococcosis-specific self-management ability $(\beta=0.252, P<0.001)$ were significant predictors of BIPE, while the dimension of information acquisition and evaluation $\operatorname{ability}(\beta=0.093, P=0.089)$ was not significantly related to BIPE.

\section{Discussion}

This study shows that the two dimensions of ES-HL, perceived echinococcosis information support and echinococcosis-specific self-management ability, were significantly associated with BIPE, while the information acquisition and evaluation ability dimension was not found to be associated with BIPE. In addition, sex and income level were also associated with BIPE.

In this study, perceived echinococcosis information support requires the ability which involves the use of cognitive and interactive skills in a social environment and supports social participation in health-related issues in the community. Therefore, the ability is a determinant of how much social information support an individual can obtain. Studies show that social support is crucial for transmitting appropriate health information and monitoring behaviors and practices among all population groups [26-27]. In the current study, the result that perceived echinococcosis information support has significant positive effects on BIPE indicate that when individuals have more perception of echinococcosis information support from the village cadres, the medical staff or family members, their BIPE will increase. This may be because more social information support means more access to information, and then individuals would have a better understanding of echinococcosis, and they are more likely to be motivated by others to take some measures to prevent echinococcosis. Consistent with our research, in the case of oral health-promoting behaviour, it was indicated that higher level in health literacy domain "Feeling understood and supported by healthcare provider" measured by Scale 1 of HLQ is associated with better oral health-promoting behaviour including tooth-brushing at least twice a day and using interdental floss[28].Besides, a study from Thailand found that "Feeling understood and supported by healthcare provider" was closed related to healthy behaviors that were affected by engaging in social health activities[29]. 
The significance of individuals' behavioral choices places their self-management at the center of diseases care and prevention models[30]. Chodosh and colleagues defined self-management as having a minimum of two components-self-monitoring and decision-making[31]. In this study, echinococcosisspecific self-management requires individuals have the skills to conduct self-assessment, participate in echinococcosis prevention services and make decisions to modify their own behavior. At present, selfmanagement ability has been widely concerned in the management of chronic diseases[32-34]. There are many studies that have also shown self-management interventions have benefits for the prevention and care of the infectious diseases, such as AIDS[35],tuberculosis[36],hepatitis C[37] and filariasis[38]. Furthermore, it has been found that health literacy domain "active managing of one's health" measured by Scale 3 of HLQ was closely related to the health risk behaviors of Danish adults, including physically inactive, unhealthy diet and smoking [39], as well as the oral health-promoting behaviours of Slovak adults[28]. It was also indicated that "active managing of one's health" scale was significantly associated with the lifestyle risk factors including smoking and being more sedentary among Geelong Osteoporosis[40]. The result of our study that echinococcosis-specific self-management ability was crucial to individual BIPE is consistent with the above studies on the association between health behaviors and self-management ability in health literacy domain.

In this study, information acquisition and evaluation ability dimension was not found to be associated with BIPE. This may be explained by the fact that most respondents recruited in this study have just finished primary school or were illiterate. Information acquisition and evaluation ability for most participants is generally at a very lower level. Therefore, it may be not a sensitive predictor of BIPE. Furthermore, the majority of herdsmen are poor and live in deprived communities, and their understanding of echinococcosis rely heavily on their social networks, so echinococcosis information channels and external echinococcosis information support may be more important than their own information acquisition and evaluation ability for the echinococcosis prevention and control in this poor and resource-limited area.

In addition, this study shows that sex is an influencing factor of the BIPE. Compared with males, the BIPE for females was lower in this study. There is a study that showed the main knowledge gaps varied between man and women[41]. For example, very few women but most men made the link between infected offal and dog infection, yet more women than men considered eating infected offal less of a health issue[41]. A health information intervention study on echinococcosis [42] also showed that the intervention had different outcomes among men and women because of the educative role and norms at the household level. Our study also showed that the BIPE in high-income people was lower than that in low-income people. This may be explained by the fact that high-income people have more cattle and sheep,and they have to spend more time and energy on herd care, so they are more likely to ignore the prevention of echinococcosis.

This study has several limitations. Firstly, this study is a cross-sectional survey, so the causal relationship between research variables can not be fully inferred. In the future, some intervention studies are needed to verify the results of this study. Secondly, the measurement tools in this study are self-developed 
questionnaires which have certain measurement bias. The reliability and validity of the scales still need to be verified in future studies. Finally, the participants of this study are Tibetan herdsmen from Gande county, Qinghai Province, China. More studies are needed to further explore and verify the research results in other regions and other ethnic groups.

\section{Conclusions}

ES-HL is an important predictor of whether individuals take preventive actions against echinococcosis. ES-HL promotion action project should be developed aiming at different target population to enhance some of the specific abilities needed to prevent echinococcosis.

\section{Abbreviations}

$\mathrm{HL}$

Health Literacy

ES-HL

Echinococcosis-Specific Health Literacy

BIPE

Behavioral Intention to Prevent Echinococcosis

E.

Echinococcus

AE

Alveolar Echinococcosis

CE

Cystic Echinococcosis

HLQ

The Health Literacy Questionnaire

HLS-EU

The European Health Literacy Survey

EFA

Explore Factor Analysis

KMO

Kaiser-Meyer-Olkin

\section{Declarations}

\section{Ethics approval and consent to participate}

The study was approved by the Medical Research Ethics Committee of the School of Public Health, Fudan University (The international registry NO. IRB00002408 \& FWA00002399). A written informed consent was obtained from each participant. 
Availability of data and materials

The datasets used and/or analysed during the current study are available from the corresponding author on reasonable request.

\section{Competing interests}

The authors declare that they have no competing interests.

\section{Funding}

This study was supported by the National Social Science Grant of China (No. 13CSH076) and Shanghai Public Health Key Discipline Plan (Nos. 12GWZX0901, 15GWZK1001).

\section{Authors' contributions}

YZDW, CDJ, BTD, BL and ZYL worked on the data collection. JZ wrote the manuscript following discussions with YZDW. JZ did the statistical analysis. WLC,JYW and YXZ revised the paper and improved the technical quality of the manuscript. JWW,ZAK and LZS were the project coordinator and participated in all parts of the work. All authors approved the final version of the paper.

\section{Acknowledgements}

We thank all those who responded to this investigation. We also thank all workers and volunteers involved in the acquisition of data.

\section{Authors' information}

Jie Zhao and Yangzong Dawa are co-first authors.

\section{References}

[1] McManus DP, Zhang W, Li J, Bartley PB. Echinococcosis. The Lancet. 2003; 362:1295-1304.

[2] Mitra AK, Mawson AR. Neglected Tropical Diseases: Epidemiology and Global Burden. Tropical medicine and infectious disease. 2017;2:36.

[3] Budke CM, Casulli A, Kern P, Vuitton DA. Cystic and alveolar echinococcosis: Successes and continuing challenges.PLoS neglected tropical diseases.2017; 11:e0005477.

[4] World Health Organization:WHO estimates of the global burden of foodborne diseases. Accessed 3 Dec 2015.

[5] Wang Q, Huang Y, Huang L, Yu W, He W, Zhong B, Li W, Zeng X, Vuitton DA, Giraudoux P, Craig PS, Wu W. Review of risk factors for human echinococcosis prevalence on the Qinghai-Tibet Plateau, China: a 
prospective for control options. Infectious Diseases of Poverty. 2014;3:3.

[6] Jin-Lei Wang, Ting-Ting Li, Si-Yang Huang, Wei Cong, Xing-Quan Zhu.Major parasitic diseases of poverty in mainland China: perspectives for better control.Infectious Diseases of Poverty. 2016;5:67.

[7] Li T, Chen X, Zhen R, Qiu J, Qiu D, Xiao N, Ito A, Wang H, Giraudoux P, Sako Y et al. Widespread coendemicity of human cystic and alveolar echinococcosis on the eastern Tibetan Plateau, northwest Sichuan/southeast Qinghai, China. Acta tropica. 2010;113:248-256.

[8] Craig PS, McManus DP, Lightowlers MW, Chabalgoity JA, Garcia HH, Gavidia CM, Gilman RH, Gonzalez $\mathrm{AE}$, Lorca $\mathrm{M}$, Naquira $\mathrm{C}$ et al. Prevention and control of cystic echinococcosis. The Lancet Infectious Diseases. 2007; 7:385-394.

[9] Moss JE, Chen X, Li T, Qiu J, Wang Q, Giraudoux P, Ito A, Torgerson PR, Craig PS. Reinfection studies of canine echinococcosis and role of dogs in transmission of Echinococcus multilocularis in Tibetan communities, Sichuan, China. Parasitology. 2013;140:1685-1692.

[10] Acha PN, Szyfres B. Zoonoses and Communicable Diseases Common to Man and Animals.3rd ed. Washington, DC: Scientific and Technical Publication;2003.

[11] Khan et al. Knowledge, attitudes and practices related to cystic echinococcosis endemicity in Pakistan.Infectious Diseases of Poverty. 2018; 7:4.

[12] Nutbeam D. The evo1ving concept of health 1iteracy.Soc Sci Med.2008;67: 2072-2078.

[13] Marks B , Sisirak J , Hsieh K. Health services, health promotion, and health literacy: Report from the State of the Science in Aging with Developmental Disabilities Conference.Disability \& Health Journal.2008;1:136-142.

[14] Schillinger D , Grumbach K, Piette J , et al. Association of health literacy with diabetes outcome. JAMA-Journal of the American Medical Association.2002; 288:475-482.

[15] U.S. Department of Health and Human Services, Office of Disease Prevention and Health Promotion: National action plan to improve health literacy. http://www.health.gov/communication/HLActionPlan. Accessed 1 February 2012.

[16] The Joint Commission. "What did the doctor say?" Improving health literacy to protect patient safety. http://www.jointcommission.org/nr/rdonlyres/d5248b2e-e7e6-4121-887499c7b4888301/0/improving_health_literacy.pdf. Accessed 1 February 2012.

[17] Wolf M, Bennett C, Davis T, Marin E, Arnold C. A qualitative study of literacy and patient response to HIV medication adherence questionnaires. Journal of Health Communication. 2005; 10: 509-517. 
[18] Kravitz RL, Hays RD, Sherbourne CD, DiMatteo MR, Rogers WH, Ordway L, et al. Recall of recommendations and adherence to advice among patients with chronic medical conditions. Arch Intern Med. 1993;153:1869-78.

[19] Lawrence PA, Cheely J. Deterioration of diabetic patients' knowledge and management skills as determined during outpatient visits. Diabetes Care. 1980;3:214-8.

[20] Sheeran P. Intention-Behavior Relations: A Conceptual and Empirical Review. In: Stroebe W, Hewstone M, editors. European Review of Social Psychology.John Wiley \& Sons, Ltd; 2002.

[21] Ajzen, I. Attitudes, Personality, and Behavior. Milton Keynes: Open University Press; 1988.

[22] Ajzen, I. From intentions to actions: A theory of planned behavior. In J. Kuhl \& J.Beckmann,editors.Action Control: From Cognition to Behavior. Berlin: Springer-Verlag; 1985.p.11-39.

[23] Sutton, S.Predicting and explaining intentions and behaviour: How well are we doing?. Journal of Applied Social Psychology.1998; 28:1317-38.

[24] Osborne R H , Batterham R W , Elsworth G R , et al. The grounded psychometric development and initial validation of the Health Literacy Questionnaire (HLQ). BMC Public Health.2013;13.

[25] Fullam J , Doyle G, Sorensen K, et al. THE DEVELOPMENT AND VALIDATION OF THE EUROPEAN HEALTH LITERACY SURVEY(HLS.EU). Irish Journal of Medical Science. 2011;180:225-226.

[26] Yang Q , Chen Y, Muhamad J W . Social Support, Trust in Health Information, and Health Information-Seeking Behaviors (HISBs): A Study Using the 2012 Annenberg National Health Communication Survey (ANHCS). Health Communication. 2016; 32:1.

[27] Oliver V , Paxton R. Mental Health Needs and Social Support in a Health Information Service. Mental Health Review Journal. 1999; 4:13-17.

[28] Cepova E , Cicvakova M , Kolarcik P , et al. Associations of multidimensional health literacy with reported oral health promoting behaviour among Slovak adults: a cross-sectional study. BMC Oral Health. $2018 ; 18: 44$.

[29] Ungsinun Intarakamhang, Yuttapong Kwanchuen. The development and application of the ABCDEhealth literacy scale for Thais. Asian Biomedicine. 2016; 10:587-594.

[30] Bodenheimer T, Lorig K, Holman H, Grumbach K. Patient self-management of chronic disease in primary care. Journal of the American Medical Association.2002;288:2469-2475.

[31] Chodosh J, Morton SC, Mojica W, Maglione M, Suttorp MJ, Hilton L, Rhodes S, Shekelle P. Metaanalysis: chronic disease self-management programs for older adults. Annals of Internal Medicine. 2005;143:427-438. 
[32] Epping-Jordan J, Bengoa R, Kawar R, Sabaté E. The challenge of chronic conditions: WHO responds. British Medical Journal. 2001;323:947-8.

[33] Glasgow RE, Toobert DJ, Barrera M, Strycker LA. Assessment of problem-solving: A key to successful diabetes self-management. Journal of Behavioral Medicine. 2004;27:477-490.

[34] Purdie N, McCrindle A.Self-regulation, self-efficacy and health behavior change in older adults. Educational Gerontology. 2002;28:379-400.

[35] Martin F , Caramlau I O , Sutcliffe P, et al. Self-management interventions for people living with HIV/AIDS.Cochrane Database of Systematic Reviews. 2010;9:CD008731.

[36] Ameen M Almohammadi, Dina S Qurashi, Ghaydaa A Abuouf. Assessment of patients' knowledge of tuberculosis and its impact on self-management ability. Tropical Journal of Pharmaceutical Research. 2019;19: 2425-2430.

[37] Groessl E J , Ho S B , Asch S M , et al. The Hepatitis C Self-Management Program. Health Education \& Behavior. 2013;40:730.

[38] Ram, Kumar, Adhikari. Health-seeking behaviors and self-care practices of people with filarial lymphoedema in Nepal: a qualitative study. Journal of Tropical Medicine.2015; 2015:1-6.

[39] Karina F , Donslund V B , Simmons R K, et al. The Relationship between Health Literacy and Health Behaviour in People with Diabetes: A Danish Population-Based Study. Journal of Diabetes Research. 2016; 2016:1-7.

[40] Hosking S M , Brennan-Olsen S L , Alison B , et al. Health literacy in a population-based sample of Australian women: a cross-sectional profile of the Geelong Osteoporosis Study. BMC Public Health. 2018; 18:876-890.

[41] Thys, Séverine, Sahibi H , Gabriël, Sarah, et al. Community perception and knowledge of cystic echinococcosis in the High Atlas Mountains, Morocco.Bmc Public Health. 2019;19.

[42] Ducrotoy MJ, Yahyaoui Azami H, El Berbri I, Bouslikhane M, Fassi Fihri O, Boué F, et al. Integrated health messaging for multiple neglected zoonoses:approaches, challenges and opportunities in Morocco. Acta Trop. 2015;152:17-25.

\section{Tables}

Table 1 Demographic characteristics of the respondents 


\begin{tabular}{|c|c|}
\hline Characteristic & Number (\%) \\
\hline \multicolumn{2}{|l|}{ Sex } \\
\hline Male & $197(49.1)$ \\
\hline Female & $204(50.9)$ \\
\hline \multicolumn{2}{|l|}{ Age } \\
\hline$<29$ & $110(27.4)$ \\
\hline $30-39$ & $120(29.9)$ \\
\hline $40-49$ & $88(21.9)$ \\
\hline$\geq 50$ & $83(20.7)$ \\
\hline \multicolumn{2}{|l|}{ Degree of education } \\
\hline Illiterate or primary school & 299 (74.6) \\
\hline Junior high school & $38(9.5)$ \\
\hline Senior high school or above & $64(16.0)$ \\
\hline \multicolumn{2}{|l|}{ Marital status } \\
\hline Married & $326(81.3)$ \\
\hline Others(unmarried,divorced, widowed) & $75(18.7)$ \\
\hline \multicolumn{2}{|l|}{ Family monthly income per capita } \\
\hline$<1000$ & $179(44.6)$ \\
\hline 1000-1999 & $112(27.9)$ \\
\hline 2000-3999 & 75 (18.7) \\
\hline$\geq 4000$ & $35(8.7)$ \\
\hline
\end{tabular}

Table legend: Table 1 summarizes the demographic characteristics of the respondents.

Table2 Results of exploratory factor analysis of ES-HL

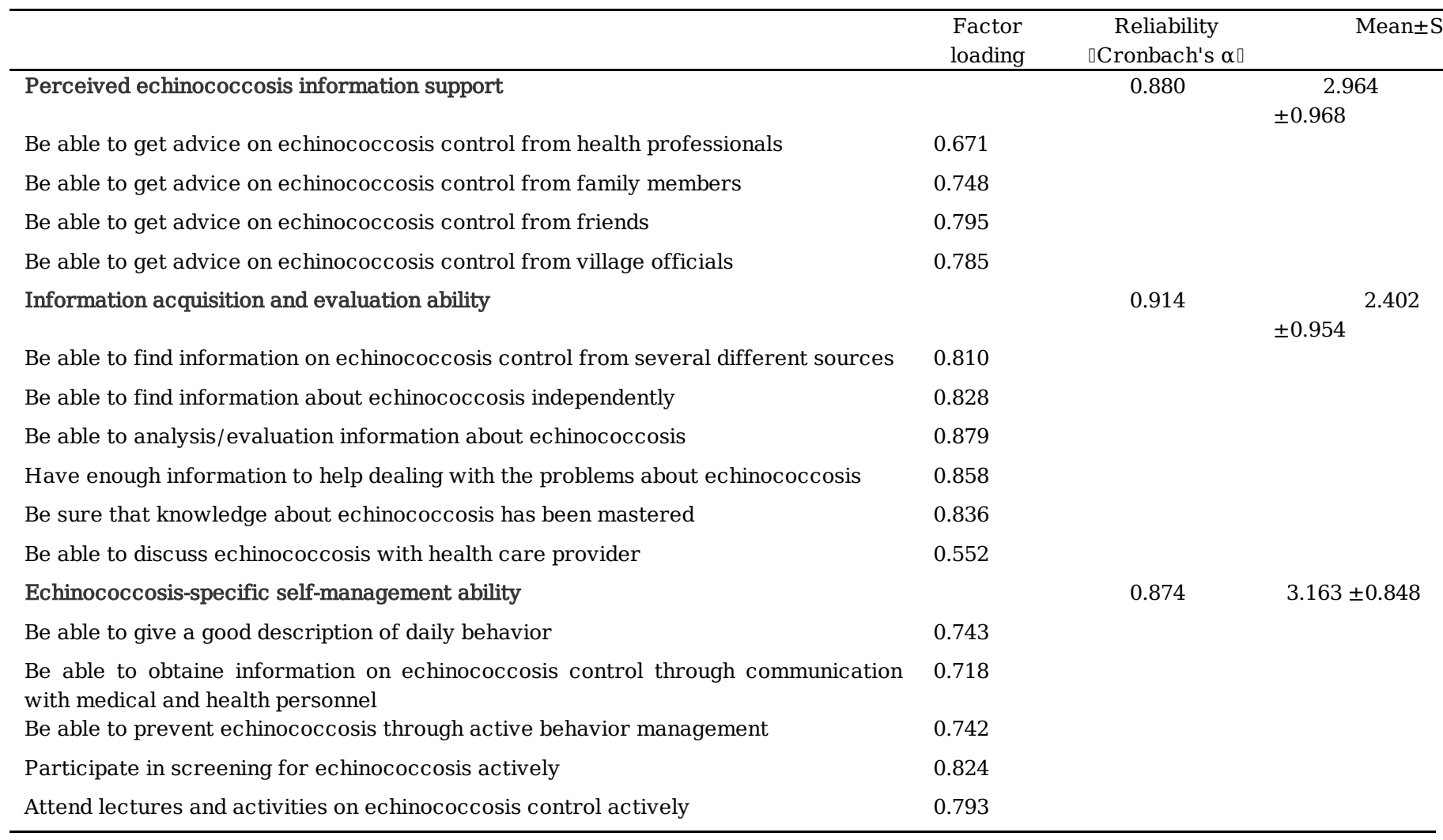

Table legend: Table 2 presents the factor loadings based on EFA, Cronbach's $\alpha$, score mean and standard deviation for these factors. 
Table3 Correlation among demographic variables,ES-HL and BIPE

\begin{tabular}{|c|c|c|c|c|c|c|c|c|c|}
\hline Characteristic & 1 & 2 & 3 & 4 & 5 & 6 & 7 & 8 & 9 \\
\hline 1. Sex & - & & & & & & & & \\
\hline 2. Age & $-0.102 *$ & - & & & & & & & \\
\hline 3. Degree of education & 0.064 & $-0.383 * * *$ & - & & & & & & \\
\hline 4. Marital status & $0.126^{*}$ & $-0.357 * * *$ & $0.384 * * *$ & - & & & & & \\
\hline 5. Family monthly income per capita & -0.004 & -0.013 & $0.159^{* *}$ & -0.017 & - & & & & \\
\hline 6. Perceived echinococcosis information support & -0.09 & $-0.141 * *$ & 0.053 & 0.015 & -0.031 & - & & & \\
\hline 7. Information acquisition and evaluation ability & -0.023 & $-0.243^{* * *}$ & $0.269 * * *$ & 0.044 & 0.081 & $0.527 * *$ & - & & \\
\hline 8. Echinococcosis-specificself-management ability & $-0.131 * *$ & 0.064 & -0.032 & -0.065 & -0.04 & $0.646^{* *}$ & $0.371^{* * *}$ & - & \\
\hline 9. BIPE & $-0.137 * *$ & 0.042 & -0.026 & -0.092 & $-0.127 *$ & $0.439^{* * *}$ & $0.283^{* *}$ & $0.454^{* *}$ & \\
\hline
\end{tabular}

Table legend: Table 3 summarizes the correlation among the demographic variables (sex, age, education level, marital status, family monthly income per capita), three factors of ES-HL and BIPE. * $\mathrm{P}<0.05, * * \mathrm{P}<0.01$, *** $\mathrm{P}<0.001$

Table4 Summary of hierarchical regression analysis for variables predicting the BIPE

\begin{tabular}{|c|c|c|c|c|}
\hline \multirow{3}{*}{ Variables } & \multicolumn{4}{|c|}{ BIPE } \\
\hline & \multicolumn{2}{|l|}{ Model 1} & \multicolumn{2}{|l|}{ Model 2} \\
\hline & $\mathrm{B}(\mathrm{SE})$ & $\beta$ & $\mathrm{B}(\mathrm{SE})$ & $\beta$ \\
\hline \multicolumn{5}{|l|}{ Block1 } \\
\hline Age & $0.082(0.342)$ & 0.013 & $0.370(0.310)$ & 0.060 \\
\hline Sex & $-1.676(0.673)$ & $-0.125^{*}$ & $-0.851(0.593)$ & -0.064 \\
\hline Degree of education & $0.390(0.511)$ & 0.044 & $0.083(0.460)$ & 0.009 \\
\hline Marital status & $-1.533(0.958)$ & -0.090 & $-1.028(0.843)$ & -0.060 \\
\hline Family monthly income per capita & $-0.901(0.343)$ & $-0.133^{* *}$ & $-0.808(0.301)$ & $-0.119 * *$ \\
\hline \multicolumn{5}{|l|}{ Block2 } \\
\hline Perceived echinococcosis information support & & & $1.581(0.437)$ & $0.229^{* * *}$ \\
\hline Information acquisition and evaluation ability & & & $0.649(0.380)$ & 0.093 \\
\hline Echinococcosis-specific self-management ability & & & $1.998(0.463)$ & $0.252^{* * *}$ \\
\hline$\triangle$ Adjust $\mathrm{R} \square$ & \multicolumn{2}{|l|}{0.029} & \multicolumn{2}{|c|}{0.229} \\
\hline F change & \multicolumn{2}{|c|}{$3.351 * *$} & \multicolumn{2}{|c|}{$40.722 * * *$} \\
\hline Final adjust $\mathrm{R}^{2}$ & \multicolumn{2}{|l|}{0.029} & \multicolumn{2}{|c|}{0.258} \\
\hline
\end{tabular}

Table legend: Table 4 reports the unstandardized (B) and standardized ( $\beta$ ) regression coefficients for model 1 and model 2 . Block1 was entered into model1. Block1 and Block2 were entered into model2. ${ }^{*} \mathrm{P}<0.05,{ }^{* *} \mathrm{P}<0.01,{ }^{* * *} \mathrm{P}<0.001$ 